\title{
A versatile polyacrylamide gel electrophoresis based sulfotransferase assay
}

\author{
Zhengliang $L$ Wu', Cheryl M Ethen, Sara Larson, Brittany Prather, Weiping Jiang
}

\begin{abstract}
Background: Sulfotransferases are a large group of enzymes that regulate the biological activity or availability of a wide spectrum of substrates through sulfation with the sulfur donor 3'-phosphoadenosine-5'-phosphosulfate (PAPS). These enzymes are known to be difficult to assay. A convenient assay is needed in order to better understand these enzymes.

Results: A universal sulfotransferase assay method based on sodium dodecyl sulfate polyacrylamide gel electrophoresis (SDS-PAGE) is described. This assay has been successfully applied to substrates as small as $\alpha$ naphthol and as big as proteoglycans. As examples, we present the assays for recombinant human CHST4, TPST1, CHST3 and HS6ST1. In order to assess whether a small molecule can be applicable to this type of assay, a method to estimate the relative mobility of a molecule to PAPS is also presented. The estimated relative mobilities of various sulfated small molecules generated by SULT1A1, SULT1E1, SULT2A1 and CHST4 are in the range of \pm 0.2 of the actual relative mobilities.

Conclusion: The versatility of the current method comes from the ability that SDS-PAGE can separate proteins and small molecules according to different parameters. While mobilities of proteins during SDS-PAGE are inversely related to their sizes, mobilities of small molecules are positively related to their charge/mass ratios. The predicted relative mobility of a product to PAPS is a good indicator of whether a sulfotransferase can be assayed with SDSPAGE. Because phosphorylation is most similar to sulfation in chemistry, the method is likely to be applicable to kinases as well.
\end{abstract}

\section{Background}

Sulfation is a ubiquitous post-translational modification that affects the biological activity of a wide variety of substrates, ranging in molecular mass from less than $10^{3}$ to greater than $10^{6} \mathrm{Da}$. The reaction is catalyzed by sulfotransferases using 3'-phosphoadenosine-5'-phosphosulfate (PAPS) ${ }^{1}$ as the sulfate donor [1]. There are 48 sulfotransferases in humans and they can be divided into two major groups according to their sub-cellular localization: those found in cytoplasm and those found in the Golgi apparatus [2]. Cytosolic sulfotransferases, commonly designated as SULTs, are mainly involved in modifying small molecules (in general $<1000 \mathrm{Da}$ in mass), such as steroids, neurotransmitters, and xenobiotics [3]. Along with P450 enzymes, SULTs play important roles in drug detoxification [4,5]. Golgi resident sulfotransferases are involved in modifying numerous

* Correspondence: leon.wu@rndsystems.com

R\&D Systems Inc, 614 McKinley Place NE, Minneapolis, MN 55413, USA glycans and proteins on the cell membranes and within extracellular matrix. Glycan sulfation is known to affect hormone pharmacokinetics [6], growth factor and cytokine activity [7], viral [8] and bacterial [9] invasion. Protein sulfation is known to be important in proteinprotein interactions, such as leukocyte adhesion molecule PSGL-1 binding to P-selectin on activated endothelium $[10,11]$.

Although the significance and pervasiveness of sulfation have gradually been realized, research on this area has been hampered by the inconvenient assay systems currently available. Usually, sulfotransferase assays rely on chromatography steps, such as HPLC [12-14] and TLC [15-17], to separate substrates and products. However, HPLC is difficult to process multiple samples and TLC is unsuitable to separate proteins and polysaccharides. Recently, HPLC coupled mass spectrometry has been applied to characterize sulfotransferase products $[18,19]$, but it is difficult to assess enzymatic activity due 
to its nature of being semiquantitative. Colorimetric [20] and fluorescent sulfotransferase assays [21] have also been explored, but these assays are limited to substrates with colorimetric or fluorescent properties. We have developed a versatile electrophoresis-based sulfotransferase assay that can be applied to substrates ranging from small molecules, such as $\alpha$-naphthol, to large molecules, such as proteoglycans, by taking advantage of the fact that both small and large molecules can be separated from PAPS during SDS-PAGE (Figure 1).

\section{Results}

\section{Assay development for rhCHST4}

As an illustration of the general procedure of assay development for all sulfotransferases, the assay for recombinant human carbohydrate sulfotransferase 4 (rhCHST4) is described here (Figure 2). CHST4, also known as high endothelial cell $\mathrm{N}$-acetylglucosamine 6O-sulfotransferase (HEC-GlcNAc6ST) or L-selectin ligand sulfotransferase (LSST), catalyzes the sulfation at the 6-O position of the non-reducing end $\mathrm{N}$-acetylglucosamine (GlcNAc) residues within mucin-associated glycans [22]. Instead of using native glycan, we used a disaccharide GlcNAcMan as the acceptor substrate.

Each rhCHST4 reaction started with 2,500 pmol acceptor substrate and 1,000 pmol of donor substrate. To locate the linear response region of rhCHST4, an activity-enzyme plot was first established from 0 to $500 \mathrm{ng}$ enzyme input in a 2 -fold serial dilution fashion (Figure 2A, Additional file 1, Table S1). The linear response region was then located from 0 to $40 \mathrm{ng}$ of enzyme input and the experiment was repeated within this region. A second activity-enzyme plot was then established and a linear regression equation was obtained based on this second plot (Figure 2B,
Additional file 1, Table S2). Because the equation was based on four consecutive data points and had correlation coefficient $R^{2}=0.990$, the slope of the equation, $391 \mathrm{pmol} / \mathrm{min} / \mu \mathrm{g}$, was then accepted as the measured specific activity of rhCHST4.

To make sure that rhCHST4 was stable over the time, a product-time plot was also conducted (Figure 2C, Additional file 1, Table S3). In this experiment, the amount of enzyme was fixed at $7.5 \mathrm{ng}$, but reaction time varied from 0 to 20 minutes. The enzyme showed a good linear product-time course (correlation coefficient $\left.\mathrm{R}^{2}=0.993\right)$, indicating that the enzyme was stable over the time. This result therefore validated the 20 minute reaction time used in previous experiments.

\section{Assay Examples}

SDS-PAGE based sulfotransferase assay has been successfully applied to all sulfotransferases that are available to us thus far. To further illustrate the versatility of this method, we describe the assays of several other representative sulfotransferases using different acceptor substrates. To avoid redundancy, only data directly showing specific activity are presented here (Figure 3).

\section{TPST1 assay using PSGL-1 peptide as the acceptor}

Tyrosylprotein sulfotransferase (TPST) transfers sulfates to the P-selectin glycoprotein ligand-1 (PSGL-1) on myeloid cells and stimulated $\mathrm{T}$ lymphocytes and plays a critical role in the tethering of these cells to activated platelets or endothelia that express P-selectin [23]. Recombinant human TPST1 (rhTPST1) was assayed using 25,000 pmol of acceptor substrate PSGL-1 peptide and $1,000 \mathrm{pmol}$ of PAPS in at $37^{\circ} \mathrm{C}$ for 20 minutes. Enzyme linear response region was located from 0 to $500 \mathrm{ng}$ of enzyme input. Under these conditions, the specific activity was determined to be $22.6 \mathrm{pmol} / \mathrm{min} / \mu \mathrm{g}$ (Figure 3A).

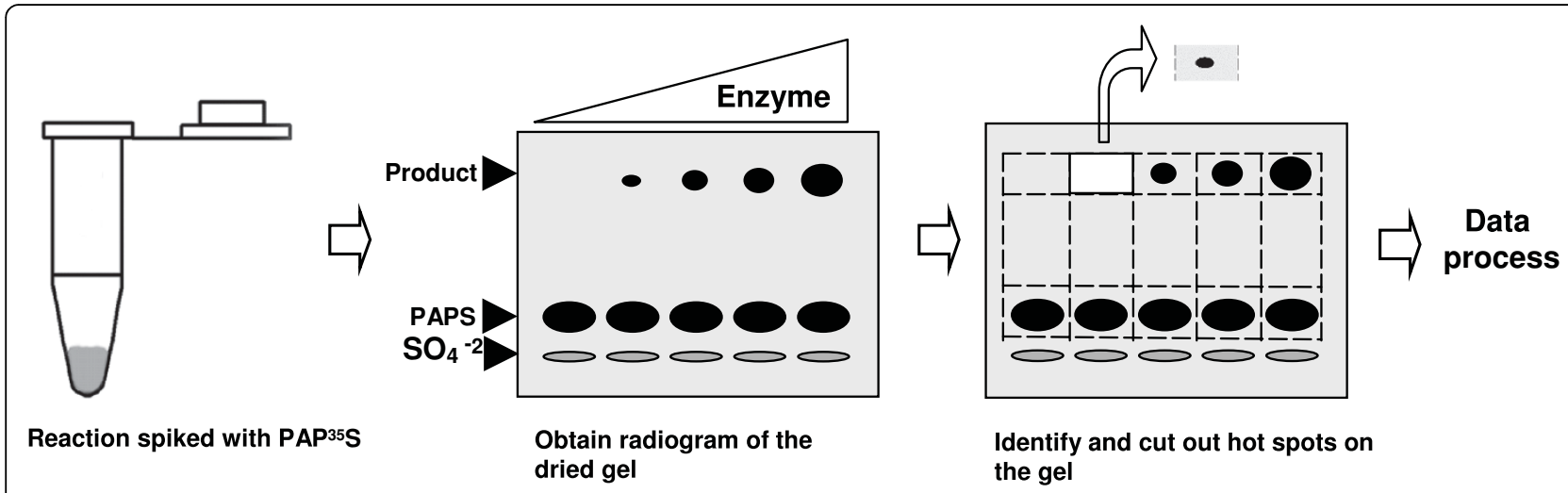

Figure 1 Scheme of electrophoresis based sulfotransferase assay. The assay mainly consists of four steps. First, spike sulfotransferase reaction with $\mathrm{PAP}^{35} \mathrm{~S}$. Second, separate the reactions on $8 \%$ SDS gel by electrophoresis and obtain an autoradiogram of the dried gel. Generation of the free sulfate is inevitable due to the degradation of PAPS. Third, cut out the hot spots on the dried gel and count the radioactivity. Fourth, data process. 


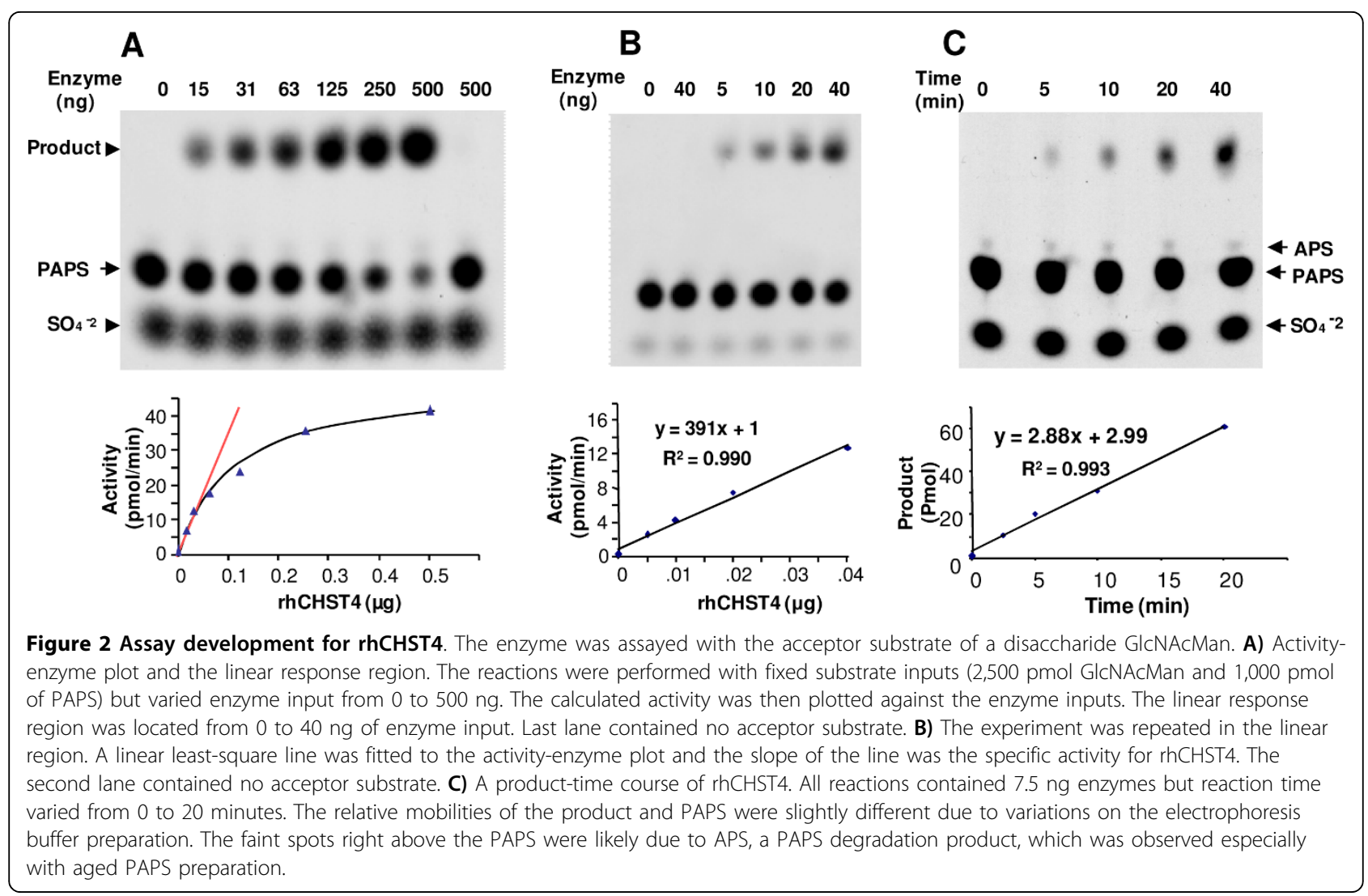

\section{CHST3 assay using chondroitin sulfate as the acceptor}

Carbohydrate sulfotransferases 3 (CHST3), also known as chondroitin 6-sulfotransferase, catalyzes the sulfation at the 6-O position of the $\mathrm{N}$-acetylgalactosamine (GalNAc) residues on chondroitin sulfate [24]. In this example, assay was done using 5,000 pmol of PAPS and $100 \mu \mathrm{g}$ of bovine chondroitin sulfate as the acceptor substrate. Other assay conditions were the same as those of rhCHST4. Under these conditions, recombinant human CHST3 (rhCHST3) showed a specific activity of $248 \mathrm{pmol} / \mathrm{min} / \mu \mathrm{g}$ (Figure 3B).

\section{HS6ST3 assay using recombinant human syndecan-4 as the acceptor}

Heparan sulfate 6-O sulfotransferase 3 (HS6ST3) transfers sulfate to the 6-O position of GlcNAc residues on heparan sulfate [25]. To assay HS6ST3, recombinant human syndecan 4, a known heparan sulfate proteoglycan, was used as the acceptor substrate. Each reaction was conducted with $10 \mu \mathrm{g}$ of acceptor substrate and $1,000 \mathrm{pmol}$ of PAPS in the presence of $0.3 \mathrm{mg} / \mathrm{mL}$ protamine. Other assay conditions were the same as those of rhCHST4. Under these conditions, recombinant human HS6ST3 (rhHS6ST3) showed a specific activity of $14 \mathrm{pmol} / \mathrm{min} / \mu \mathrm{g}$ (Figure $3 \mathrm{C}$ ). This experiment also proved that the recombinant syndecans 4 carried functional heparan sulfate.

\section{Relative Mobility of a Small Molecule to PAPS}

It is clear that the ability of SDS-PAGE to separate both large molecules, such as recombinant syndecans 4 , and small molecules, such as PAPS, is essential to the current assay systems. While it is known that protein separation in SDS-PAGE is mainly due to differences in molecular size, the separation of small molecules during electrophoresis is not well studied. To see whether a small molecule can be separated from PAPS and be applicable to the current assay method, we defined ideal mobility $(M)$ as the speed that the small molecule travels in a constant electric field without any resistance. According to this definition, the following equation was derived (Additional file 2),

$$
M=\frac{1}{2} E t \cdot \frac{q}{m}
$$

$q$, charge; $m$, mass; $E$, electric field strength; $t$, running time.

Eq. 1 indicates that the mobility of a small molecule under ideal conditions is dependent on electric field strength, running time, and, $q / m$ ratio. For all molecules in a same electrophoresis, electric field strength and running time are always the same, but the $q / m$ ratios are unique to the molecules. In order to have a more 

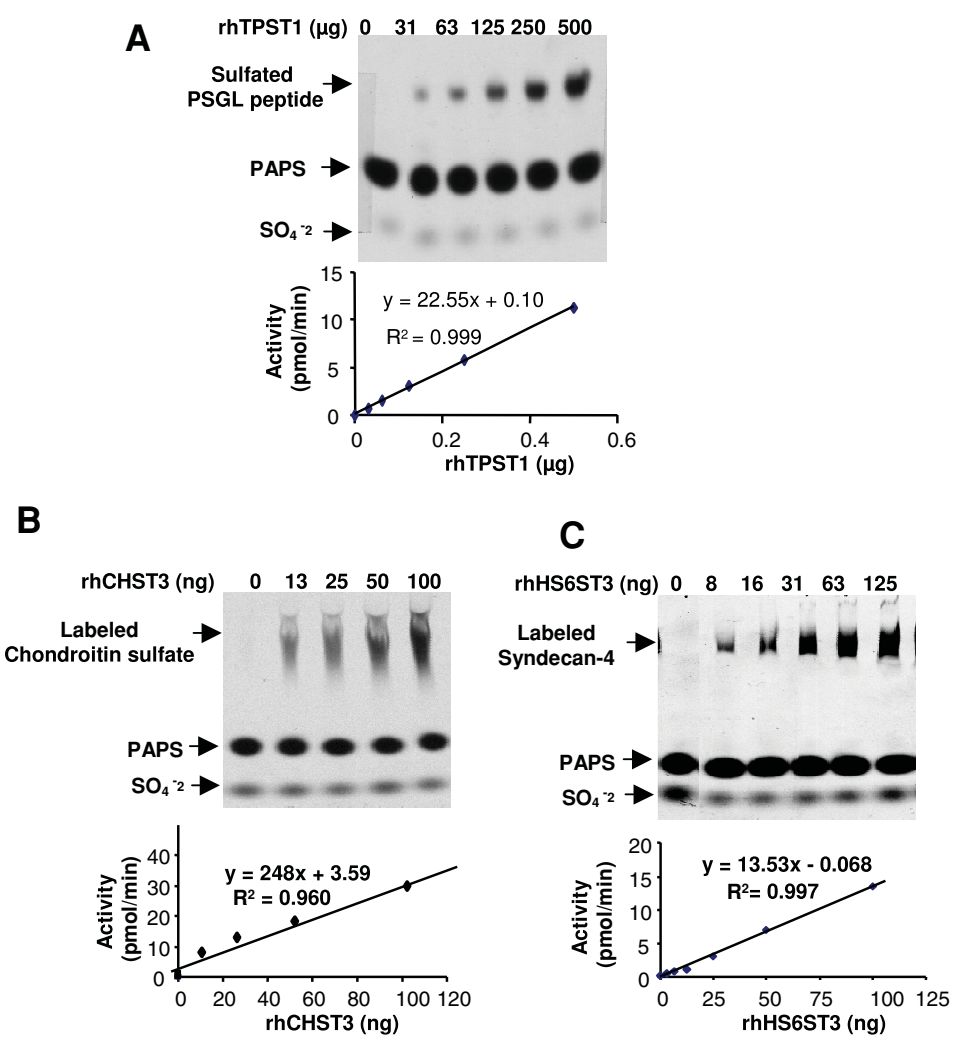

Figure 3 Examples showing the versatility of the sulfotransferase assay. A) rhTPST1 assay using PSGL-1 peptide as the acceptor. B) rhCHST3 assay using chondroitin sulfate as the acceptor. C) rhHS6ST3 assay using recombinant human syndecan-4 as the acceptor. See text for experimental conditions.

convenient term for sulfotransferase assay, we further defined relative mobility $\left(M^{\prime}\right)$ of a small molecule as the ratio of its mobility to that of PAPS $\left(M_{p}\right)$.

$$
M^{\prime}=\frac{M}{M_{p}}=\frac{q / m}{q_{p} / m_{p}}
$$

Since the charge and mass of PAPS $\left(q_{p}\right.$ and $m_{p}$ respectively) under defined conditions are constant, $M$, of a small molecule is only dependent on its own $\mathrm{q} / \mathrm{m}$ ratio. The value of $M^{\prime}$ 'suggests whether the molecule can be separated from PAPS during electrophoresis. The estimated relative mobilities of some small molecules encountered in this report are listed in Table 1. Because most of the sulfated small molecules have estimated relative mobilities less than 1 , meaning that they move slower than PAPS in an electrophoresis, these molecules are likely to be applicable to SDS-PAGE based sulfotransferase assay.

\section{Estimated Relative Mobility Correlated Well with Observed Mobility}

To see how the estimated relative mobilities correlate to the actual relative mobilities for the small molecules listed in Table 1 and further prove that this electrophoresis based assay can be applied to these small molecules, we sulfated corresponding small molecule substrates using SULT1A1, SULT1E1, SULT2A1 and CHST4, and then separated the reactions on an $8 \%$ SDS gel (Figure 4). Except the reaction for SULT1A1/dopamine where two products were observed, one product resulted in other reactions.

According to the definition of mobility, the relative mobility of a small molecule should also be equal to the ratio of the distance that it travels $(L)$ and the distance that PAPS travels $\left(L_{p}\right)$, i.e.

$$
M^{\prime}=\frac{M}{M_{p}}=\frac{L / t}{L_{p} / t}=\frac{L}{L_{p}}
$$

The distances of the products and PAPS traveled in Figure 4 were then measured and the observed relative mobilities of these products were obtained (Table 1). The observed values were in the range of \pm 0.2 of the estimated values.

The slow and fast moving bands in the SULT1A1/ dopamine reaction (lane 2, Figure 4) are likely due to mono- and di-sulfated dopamine respectively, because 
Table 1 Estimated and observed relative mobilities of some of the small molecules that were encountered in this report.

\begin{tabular}{|c|c|c|c|c|c|c|c|}
\hline Molecules $^{\mathrm{a}}$ & Charges $^{\mathrm{b}}$ on $-\mathrm{SO}_{3}{ }^{-}$ & Other Charges $^{\mathbf{b}}$ & $q$ & $m$ & $q / m \times 1000$ & $\begin{array}{c}\text { Estimated Relative } \\
\text { mobility }\left(M^{\prime}\right)\end{array}$ & $\begin{array}{c}\text { Observed relative } \\
\text { mobility }\end{array}$ \\
\hline Dopamine-1S & -1 & $+1^{c}$ & 0 & 234.2 & 0.00 & 0.00 & 0.05 \\
\hline GlcNAc-Man-1S & -1 & 0 & -1 & 477.4 & -2.09 & 0.35 & 0.35 \\
\hline Estradiol-1S & -1 & 0 & -1 & 352.4 & -2.84 & 0.48 & 0.37 \\
\hline DHEA-1S & -1 & 0 & -1 & 367.5 & -2.72 & 0.46 & 0.45 \\
\hline Lithocholic acid-1S & -1 & -1 & -2 & 455.6 & -4.39 & 0.74 & 0.63 \\
\hline Dopamine-2S & -2 & $0 \sim+1^{d}$ & $-2 \sim-1$ & $312.2 / 313.2$ & $-3.19 \sim-6.39$ & $0.54 \sim 1.07$ & 0.72 \\
\hline$\alpha$-Naphthol-1S & -1 & 0 & -1 & 224.2 & -4.46 & 0.75 & 0.80 \\
\hline p-nitrophenol-1S & -1 & 0 & -1 & 218.1 & -4.59 & 0.77 & 0.96 \\
\hline APS & -1 & -1 & -2 & 425.28 & -4.70 & 0.79 & 0.96 \\
\hline PAPS & -1 & -2 & $-3^{e}$ & 504.3 & -5.95 & 1.00 & 1.00 \\
\hline Bromophenol blue $^{f}$ & & -2 & -2 & 668 & -2.99 & 0.50 & 0.63 \\
\hline Free sulfate & & -2 & -2 & 96 & -20.83 & 3.5 & 1.24 \\
\hline
\end{tabular}

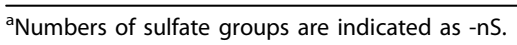

${ }^{\mathrm{b}}$ The charge numbers on the molecules were estimated based on the numbers of their charged groups, such as $-\mathrm{COO}^{-},-\mathrm{NH}_{3}{ }^{+}$and $-\mathrm{SO}_{3}{ }^{-}$. Because some functional groups were partially charged due to the influence of other neighboring functional groups, the corresponding charge number and relative mobility were only estimation.

${ }^{\mathrm{C}}$ Assuming the $-\mathrm{NH}_{3}{ }^{+}$on mono-sulfated dopamine (estimated $\mathrm{pKa}=9.5$ ) is completely protonated at $\mathrm{pH} 8.0$.

${ }^{d}$ Assuming the amine group on the di-sulfated dopamine can only partially protonated, because the two negatively charged sulfate groups could shift the pKa of the $-\mathrm{NH}_{3}{ }^{+}$closer to 8.0 .

e Fully charged PAPS would have a charge number of -4 ; however, under the assay conditions, PAPS could be partially charged and the charge number -3 was assumed here. The most similar molecule, ATP, can exist in MgATP ${ }^{2-}$, ATP ${ }^{4-}$ and ATP $^{3-}$ species [34] and overall charge number could be close to -3 too.

Bromophenol blue has about half of the mobility of PAPS and is used as an indicator during electrophoresis.

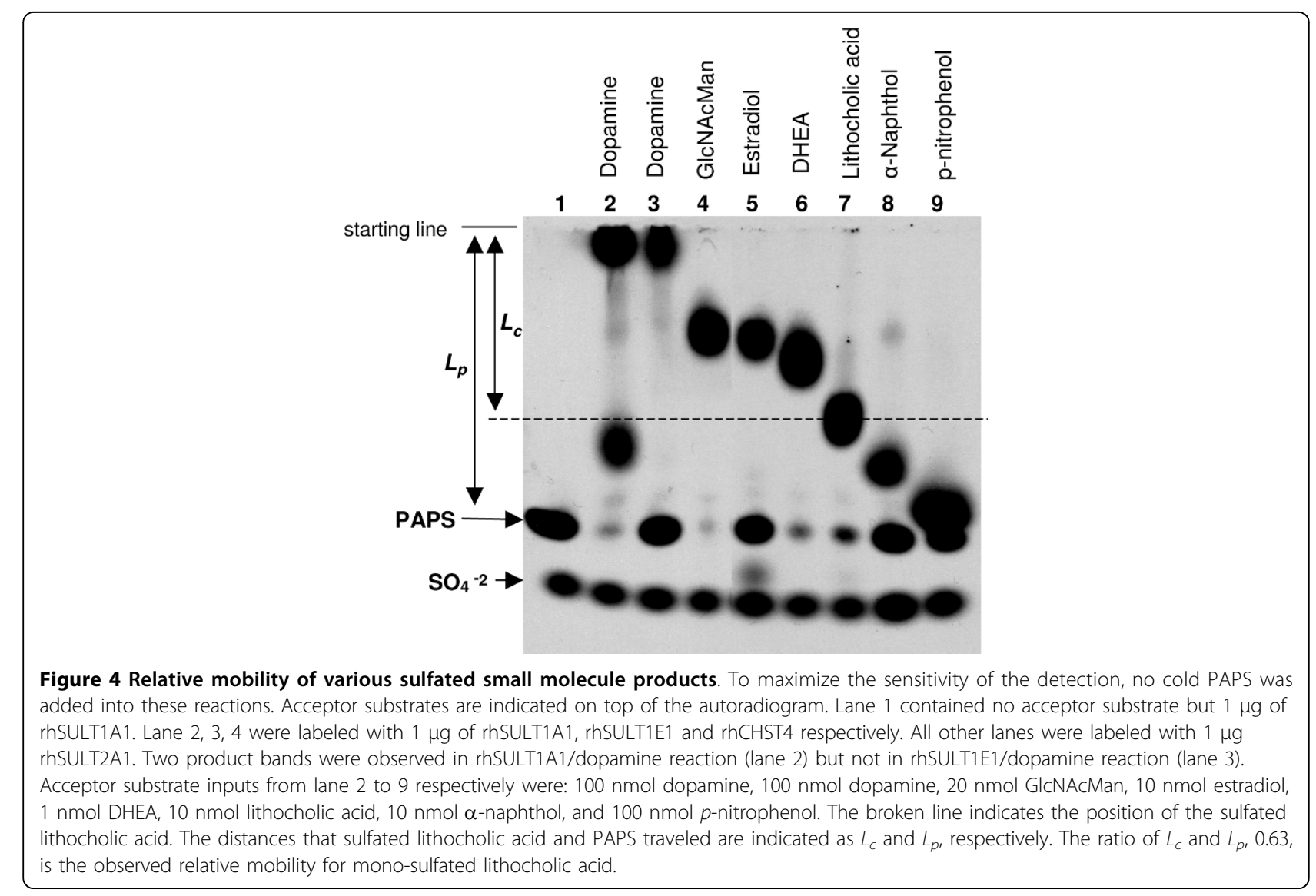


their observed relative mobilities correlate well with the estimated relative mobilities for mono- and di-sulfated dopamine respectively. While PAPS was almost completely consumed in some reactions (lane 4 and 6, Figure $4)$, significant amount of PAPS remained in other reactions (lane 3, 5, 8, Figure 4). In each reaction, PAPS was consumed by enzymatic sulfation, the rate of which was determined by enzyme kinetics, as well as degradation, which was evidenced by the presence of free sulfate in each reaction. It was to our advantage to leave some PAPS unconsumed so that we could determine the relative mobilities of the products.

\section{Discussion}

We have developed a sulfotransferase assay in which the separation of sulfated products and donor substrate PAPS is achieved using electrophoresis. In each sulfotransferase assay, an activity-enzyme plot was first obtained to locate the linear response region; a second experiment was then performed within this linear region. The specific activity of the enzyme was the slope of the linear regression equation that was obtained upon the second activity-enzyme plot. Normally, the linear response region was within low percentage of PAPS consumption $(<30 \%)$ to avoid the buildup of the side products including 3'-phosphoadenosine-5'-phosphate (PAP) and adenosine-5'-phosphosulfate (APS). PAP is reported to be a potent inhibitor to several sulfotransferases [26]. The affect of APS to the assay is less clear and the buildup of APS was only seen in aged PAPS preparation. Because sulfotransferase activities are also highly dependent on substrate concentrations due to normal enzyme kinetics and substrate inhibitions that are unique to some of the sulfotransferases [3,27], all initial substrate inputs were specified in each assay.

This electrophoresis based sulfotransferase assay can be applied to substrates as small as $\alpha$-naphthol and as large as recombinant proteoglycans. This versatility comes from that SDS-PAGE can separate large proteins and small molecules based on different parameters. Separation of proteins, including proteoglycans, is largely based on size. Separation of small molecules is largely based on $q / m$ ratio. For cases where small molecules are used as acceptor substrates, the estimated relative mobility of a sulfated product to PAPS can be used to predict whether the molecule is suitable for electrophoresis-based sulfotransferase assay.

The estimated relative mobility correlated better with the observed values for molecules with defined charge numbers, such as DHEA-1S and GlcNAc-Man-1S, than the molecules with uncertain charge numbers, such as dopamine-2S and lithocholic acid-1S (Table 1). This uncertainty was because of the unknown protonation states of some functional groups that were influenced by neighboring functional groups. A much larger deviation of the estimated relative mobility from the observed relative mobility was observed for free sulfate, which may be due to much stronger counter-ion interaction during electrophoresis.

Although the current method was developed based on assaying various purified recombinant sulfotransferases, it could be applied to assaying enzyme mixture that contains multiple sulfotransferases, as long as the enzymes are specific for different substrates. For example, if an extract contains both HS6ST1 and GalNAc4S6S, we can first assay HS6ST1 activity with heparan sulfate as the acceptor, and then assay GalNAc4S6S activity with chondroitin sulfate A as the acceptor. In general, when a certain type of glycosaminoglycan is used as acceptor, the position of the introduced sulfate is determined by the specificity of the sulfotransferase. However, it is hard to determine the exact sugar residues on a glycosaminoglycan chain that the sulfate is introduced into. To do that, we need more sophisticate methods, such as stable isotope labeling with mass spectrometry analysis [28].

The current electrophoresis-based assay offers several advantages. First, this method allows processing multiple samples simultaneously; therefore it is amenable to inhibitor screening and drug development. Although the current format using standard polyacrylamide gel electrophoresis apparatus is kind of cumbersome, it is possible to miniaturize the systems by taking advantage of scientific advances, such as nanotechnology, and to make the system high-throughput in a similar way that DNA sequencing technology was transformed from polyacrylamide gel electrophoresis based method. Second, it easily separates mono-sulfated and di-sulfated small molecule products, as suggested in the reaction with dopamine and SULT1A1. Although mono-sulfated dopamine with sulfation at either 3-O or 4-O position was reported previously [29], di-sulfated dopamine containing both 3-O and 4$\mathrm{O}$ sulfates has not been reported, probably due to the difficult on separating the two species using traditional methods. The observation of di-sulfated dopamine demonstrates how flexible the substrate binding site of SULT1A1 is [30]. Third, the electrophoresis-based assay is so versatile that it has been successfully applied to all kinds of substrates that have been tested so far. These substrates include proteoglycans, glycosaminoglycans, oligosaccharides and various phenolic small molecules. Finally, because sulfation is biochemically most similar to phosphorylation, it can be reasonably assumed that this method is applicable to kinase assay as well. 


\section{Conclusions}

We have demonstrated the versatility of PAGE-based sulfotransferase assay with several representative enzymes, which include carbohydrate and tyrosylprotein specific sulfotransferases. Small molecule specific sulfotransferases such as SULT1A1 can be assayed as long as the sulfated product has different mobility than the donor substrate PAPS. A method for predicting whether a sulfotransferase can be assayed with the current method has also been provided.

\section{Methods}

$\mathrm{PAP}^{35} \mathrm{~S}$ was synthesized from carrier free $\mathrm{Na}_{2}{ }^{35} \mathrm{SO} 4(43$ $\mathrm{Ci} / \mathrm{mg}$, from American Radiolabeled Chemicals, Inc.), ATP and phosphoenol pyruvate using ATP sulfurylase, inorganic pyrophosphatase, pyruvate kinase and APS kinase, and purified as previously described [31,32]. APS kinase (EC 2.7.1.25) was a gift from Dr. Andrew J. Fisher (University of California-Davis). ATP sulfurylase and inorganic pyrophosphatase were from New England Biolabs. Chondroitin Sulfate, GlcNAc $\beta 1-6$ Man $\alpha 1-\mathrm{OMe}$ (GlcNAcMan), heparan sulfate, dopamine, estradiol, DHEA, lithocholic acid, $\alpha$-naphthol, $p$-nitrophenol, phosphoenol pyruvate and pyruvate kinase were from Sigma-Aldrich. Recombinant syndecan-4 was from R\&D Systems. PSGL-1 peptide (QATEYEYLDYDFLPET) was synthesized according to NCBI accession number NP_002997. Cold PAPS was purchased from EMD Biosciences (Cat. No. 118410).

All sulfotransferases were expressed as $\mathrm{N}$-terminal $6 \times$ His tagged recombinant proteins. For Golgi resident sulfotransferases, only the luminal enzymatic domains were expressed in $\mathrm{CHO}$ cells as secreted forms. For cytosolic sulfotransferases, whole protein sequences were expressed in $E$. coli. The recombinant enzymes were first purified with $\mathrm{Ni}$-affinity resin and then Superdex ${ }^{\text {ma }}$ gel filtration or ion-exchange columns (GE Healthcare). Protein concentrations were quantified with Bradford assay [33].

In a typical sulfotransferase reaction, a specified amount of cold PAPS (normally $=1000$ pmol), spiked with $>10^{6} \mathrm{CPM}$ of $\mathrm{PAP}^{35} \mathrm{~S}$ (< 0.1 picomol), was mixed with specified amounts of acceptor substrate and enzyme in an assay buffer that contained $25 \mathrm{mM} \mathrm{MES}$, $0.5 \%(\mathrm{w} / \mathrm{v})$ Triton $^{\circ}-\mathrm{X} 100,2.5 \mathrm{mM} \mathrm{MgCl}_{2}, 2.5 \mathrm{mM}$ $\mathrm{MnCl}_{2}, 1.25 \mathrm{mM} \mathrm{CaCl}$, and $0.75 \mathrm{mg} / \mathrm{ml} \mathrm{BSA}$ at $\mathrm{pH} 7.0$ $(1 \times$ assay buffer $)$ in a final volume of $30 \mu \mathrm{L}$. The reaction was then incubated at $37^{\circ} \mathrm{C}$ for 20 minutes and stopped with $6 \times$ SDS stop/loading buffer $(100 \mathrm{mM}$ Tris, $10 \%$ SDS, 30\% glycerol, $60 \mathrm{mM} \beta$-mercaptoethanol, and $0.01 \%$ bromophenol blue, $\mathrm{pH} 8.0$ ). The 20 -minute reaction time was adopted for all sulfotransferase assays, because most enzymes were found reasonably stable over this period of time at the specified reaction conditions. The reaction was then loaded onto a vertical $8 \%$ SDS polyacrylamide gel (Gel buffer: $1.5 \mathrm{M}$ Tris at $\mathrm{pH}$ 8.0 with $0.4 \%$ SDS). The gel was then subjected to electrophoresis at a constant voltage of 200 volts $(\sim 10 \mathrm{v} /$ $\mathrm{cm})$ with a running buffer $(50 \mathrm{mM}$ Tris at $\mathrm{pH} 8.0)$ for 25 minutes or till the dye (bromophenol blue) was half way to the bottom of the gel. Under these conditions, PAPS would be retained on the gel.

The gel was then transferred onto a cellulose chromatography paper (Fisher Scientific, Cat\# 05714-1) and dried in a gel dryer at $80^{\circ} \mathrm{C}$ under vacuum. The dried gel was tagged with two Glogos ${ }^{\circ}$ II autorad markers (Stratagene, Catalog \# 420202) and exposed to X-ray film for a minimum of two hours. After the film was developed, the positions of the product and $\mathrm{PAP}^{35} \mathrm{~S}$ were identified by overlaying the autoradiogram and gel using the markers for alignment. The hot spots were then cut out and counted with a LS 6500 scintillation counter in Ready Safe ${ }^{\mathrm{tm}}$ cocktail (Beckman Coulter). The activity of each reaction was calculated with the following equation,

$$
\text { Activity }=S \cdot C_{i} / C_{t} \cdot 1 / t,
$$

$S$ donor substrate input; $C_{i}$ incorporated counts; $C_{t}$ total counts including incorporated and unincorporated; $t$ reaction time. Because the actual contribution from $\mathrm{PAP}^{35} \mathrm{~S}$ was negligible, the donor input $S$ was calculated only based on cold PAPS.

For specific activity determination, an activity-enzyme response plot (activity against enzyme input) was first established based on multiple reactions that covered a wide range of enzyme inputs to locate the linear response region. A second activity-enzyme response plot was then repeated only within this linear response region. The slope of the linear regression equation of this second activity-enzyme plot was then taken as the measured specific activity of the enzyme. For accuracy, the specific activity was considered to be acceptable, only if the equation was based on at least three consecutive points in a two-fold series dilution fashion and had the linear regression coefficient $R^{2}>0.96$.

\footnotetext{
Additional file 1: Data calculation for Figure 2. This file contains the raw data and activity calculation for Figure 2 . The raw data include the enzyme input and the radio isotope counts for the product and free PAPS in each reaction. Activity calculation was based on the equation Activity $=S \cdot C_{i} / C_{t} \cdot 1 / t$, (Eq.4). $C_{i}$, incorporated counts found in product; $C_{\text {paps }}$, counts of free PAPS; $C_{t}$, total counts; $S$, donor substrate input; $t$, time. The calculated activities were then plotted out against the enzyme inputs in Figure 2.

Click here for file

[http://www.biomedcentral.com/content/supplementary/1472-6750-1011-S1.DOC]
} 
Additional file 2: Induction of Equation 1. This file describes how the equation for ideal mobility of a charged small molecule,

$$
M=\frac{1}{2} E t \cdot \frac{q}{m}, \text { was obtained. }
$$

Click here for file

[http://www.biomedcentral.com/content/supplementary/1472-6750-1011-S2.DOC]

\section{Abbreviations}

APS: adenosine 5'-phosphosulfate; CHST: carbohydrate sulfotransferase; CPM: counts per minute; DHEA: dehydroepiandrosterone; GICNAc: Nacetylglucosamine; GlcNAcMan: methyl 6-O-(N-acetyl- $\beta$-D-glucosaminyl)- $\alpha$-Dmannopyranoside; HS6ST: heparan sulfate 6-O sulfotransferase; PAPS: $3^{\prime}-$ phosphoadenosine-5'-phosphosulfate; PAP: 3'-phosphoadenosine-5'phosphate; PSGL-1: P-selectin glycoprotein ligand-1; rh: recombinant human; SDS-PAGE: sodium dodecyl sulfate polyacrylamide gel electrophoresis; SULT: cytosolic sulfotransferase; TPST: tyrosylprotein sulfotransferase.

\section{Acknowledgements}

This work was supported by R\&D Systems Inc. We want to thank our colleagues, especially those in the departments of Molecular Biology and Cell Culture at R\&D Systems who made contributions to the project through expressing all the recombinant sulfotransferases mentioned in the text.

\section{Authors' contributions}

ZLW conceived the study, designed and performed the experiments and wrote the manuscript. CE performed the experiments and participated in the manuscript writing. SL and BP performed the experiments. WJ participated in the manuscript writing. All authors read and approved the final manuscript.

\section{Competing interests}

The authors declare that they have no competing interests.

The authors are employee of R\&D Systems and all researches were founded by R\&D Systems. The authors don't have any other financial competing interests.

Received: 12 July 2009

Accepted: 10 February 2010 Published: 10 February 2010

\section{References}

1. Strott CA: Sulfonation and molecular action. Endocr Rev 2002, 23(5):703-732.

2. de Graffenried CL, Laughlin ST, Kohler JJ, Bertozzi CR: A small-molecule switch for Golgi sulfotransferases. Proc Natl Acad Sci USA 2004, 101(48):16715-16720.

3. Gamage N, Barnett A, Hempel N, Duggleby RG, Windmill KF, Martin JL, McManus ME: Human sulfotransferases and their role in chemical metabolism. Toxicol Sci 2006, 90(1):5-22.

4. Nowell S, Falany CN: Pharmacogenetics of human cytosolic sulfotransferases. Oncogene 2006, 25(11):1673-1678.

5. Jakoby WB, Ziegler DM: The enzymes of detoxication. J Biol Chem 1990, 265(34):20715-20718

6. Baenziger JU, Kumar S, Brodbeck RM, Smith PL, Beranek MC: Circulatory half-life but not interaction with the lutropin/chorionic gonadotropin receptor is modulated by sulfation of bovine lutropin oligosaccharides. Proc Natl Acad Sci USA 1992, 89(1):334-338.

7. Lortat-Jacob H, Grosdidier A, Imberty A: Structural diversity of heparan sulfate binding domains in chemokines. Proc Natl Acad Sci USA 2002, 99(3):1229-1234

8. Shukla D, Liu J, Blaiklock P, Shworak NW, Bai X, Esko JD, Cohen GH, Eisenberg RJ, Rosenberg RD, Spear PG: A novel role for 3-O-sulfated heparan sulfate in herpes simplex virus 1 entry. Cell 1999, 99(1):13-22.

9. Pethe K, Alonso S, Biet F, Delogu G, Brennan MJ, Locht C, Menozzi FD: The heparin-binding haemagglutinin of $\mathrm{M}$. tuberculosis is required for extrapulmonary dissemination. Nature 2001, 412(6843):190-194.
10. Wilkins PP, Moore KL, McEver RP, Cummings RD: Tyrosine sulfation of Pselectin glycoprotein ligand-1 is required for high affinity binding to Pselectin. J Biol Chem 1995, 270(39):22677-22680.

11. Ouyang $Y$, Lane WS, Moore KL: Tyrosylprotein sulfotransferase: purification and molecular cloning of an enzyme that catalyzes tyrosine O-sulfation, a common posttranslational modification of eukaryotic proteins. Proc Natl Acad Sci USA 1998, 95(6):2896-2901.

12. Liu J, Shworak NW, Sinay P, Schwartz JJ, Zhang L, Fritze LM, Rosenberg RD: Expression of heparan sulfate D-glucosaminyl 3-O-sulfotransferase isoforms reveals novel substrate specificities. J Biol Chem 1999, 274(8):5185-5192.

13. Reinen J, Vriese E, Glatt H, Vermeulen NP: Development and validation of a fluorescence HPLC-based screening assay for inhibition of human estrogen sulfotransferase. Anal Biochem 2006, 357(1):85-92.

14. Ohtake S, Kimata K, Habuchi O: A unique nonreducing terminal modification of chondroitin sulfate by $\mathrm{N}$-acetylgalactosamine 4-sulfate 6o-sulfotransferase. J Biol Chem 2003, 278(40):38443-38452.

15. Shailubhai K, Khai Huynh Q, Boddupalli H, Yu HH, Jacob GS: Purification and characterization of a lymph node sulfotransferase responsible for 6-O-sulfation of the galactose residues in 2'-fucosyllactose and other sialyl LewisX-related sugars. Biochem Biophys Res Commun 1999, 256(1):170-176.

16. Ramaswamy SG, Jakoby WB: Sulfotransferase assays. Methods Enzymol 1987, 143:201-207.

17. Farrell DF, McKhann GM: Characterization of cerebroside sulfotransferase from rat brain. J Biol Chem 1971, 246(15):4694-4702.

18. Danan LM, Yu Z, Hoffhines AJ, Moore KL, Leary JA: Mass spectrometric kinetic analysis of human tyrosylprotein sulfotransferase-1 and -2. J Am Soc Mass Spectrom 2008, 19(10):1459-1466.

19. Pi N, Armstrong Jl, Bertozzi CR, Leary JA: Kinetic analysis of NodST sulfotransferase using an electrospray ionization mass spectrometry assay. Biochemistry 2002, 41(44):13283-13288.

20. Frame LT, Ozawa S, Nowell SA, Chou HC, Delongchamp RR, Doerge DR, Lang NP, Kadlubar FF: A simple colorimetric assay for phenotyping the major human thermostable phenol sulfotransferase (SULT1A1) using platelet cytosols. Drug Metab Dispos 2000, 28(9):1063-1068.

21. Beckmann JD: Continuous fluorometric assay of phenol sulfotransferase. Anal Biochem 1991, 197(2):408-411.

22. Bistrup A, Bhakta S, Lee JK, Belov YY, Gunn MD, Zuo FR, Huang CC, Kannagi R, Rosen SD, Hemmerich S: Sulfotransferases of two specificities function in the reconstitution of high endothelial cell ligands for $L$ selectin. J Cell Biol 1999, 145(4):899-910.

23. Pouyani T, Seed B: PSGL-1 recognition of P-selectin is controlled by a tyrosine sulfation consensus at the PSGL-1 amino terminus. Cell 1995 83(2):333-343.

24. Fukuta M, Kobayashi $Y$, Uchimura K, Kimata K, Habuchi O: Molecular cloning and expression of human chondroitin 6-sulfotransferase. Biochim Biophys Acta 1998, 1399(1):57-61.

25. Habuchi $H$, Kobayashi M, Kimata K: Molecular characterization and expression of heparan-sulfate 6-sulfotransferase. Complete cDNA cloning in human and partial cloning in Chinese hamster ovary cells. J Biol Chem 1998, 273(15):9208-9213.

26. Rens-Domiano SS, Roth JA: Inhibition of $M$ and $P$ phenol sulfotransferase by analogues of 3 '-phosphoadenosine-5'-phosphosulfate. J Neurochem 1987, 48(5):1411-1415.

27. Lu LY, Hsieh YC, Liu MY, Lin YH, Chen CJ, Yang YS: Identification and characterization of two amino acids critical for the substrate inhibition of human dehydroepiandrosterone sulfotransferase (SULT2A1). Mol Pharmacol 2008, 73(3):660-668.

28. Wu ZL, Lech M, Beeler DL, Rosenberg RD: Determining heparan sulfate structure in the vicinity of specific sulfotransferase recognition sites by mass spectrometry. J Biol Chem 2004, 279(3):1861-1866.

29. Yamamoto $T$, Yamatodani A, Nishimura $M$, Wada $H$ : Determination of dopamine-3- and 4-O-sulphate in human plasma and urine by anionexchange high-performance liquid chromatography with fluorimetric detection. J Chromatogr 1985, 342(2):261-267.

30. Gamage NU, Duggleby RG, Barnett AC, Tresillian M, Latham CF, Liyou NE, McManus ME, Martin JL: Structure of a human carcinogen-converting enzyme, SULT1A1. Structural and kinetic implications of substrate inhibition. J Biol Chem 2003, 278(9):7655-7662. 
31. Wu ZL, Zhang L, Beeler DL, Kuberan B, Rosenberg RD: A new strategy for defining critical functional groups on heparan sulfate. Faseb J 2002, 16(6):539-545.

32. MacRae IJ, Segel IH, Fisher AJ: Crystal structure of adenosine 5'phosphosulfate kinase from Penicillium chrysogenum. Biochemistry 2000, 39(7):1613-1621.

33. Bradford MM: A rapid and sensitive method for the quantitation of microgram quantities of protein utilizing the principle of protein-dye binding. Anal Biochem 1976, 72:248-254.

34. Storer AC, Cornish-Bowden A: Concentration of MgATP2- and other ions in solution. Calculation of the true concentrations of species present in mixtures of associating ions. Biochem J 1976, 159(1):1-5.

doi:10.1186/1472-6750-10-11

Cite this article as: Wu et al:: A versatile polyacrylamide gel

electrophoresis based sulfotransferase assay. BMC Biotechnology 2010

10:11.

Submit your next manuscript to BioMed Central and take full advantage of:

- Convenient online submission

- Thorough peer review

- No space constraints or color figure charges

- Immediate publication on acceptance

- Inclusion in PubMed, CAS, Scopus and Google Scholar

- Research which is freely available for redistribution

Submit your manuscript at www.biomedcentral.com/submit
C Biomed Central 